\title{
Secondary Uses of Personal Data for Population Research
}

\author{
SABRINA FORTIN, BARTHA MARIA KNOPPERS ${ }^{1}$
}

\begin{abstract}
In genomic research, cohort and large-scale population studies are proliferating along with accompanying infrastructures (databases and biobanks). Population-based research links samples and data from multiple sources often obtained for other purposes. The normative frameworks of many countries are largely based on 1980 OECD principles which limit the uses of personal data, especially for secondary purposes. These limits, now found in legislation, policies and research guidelines, pose major barriers to population-based research.
\end{abstract}

This text examines similarities and differences between epidemiology, public health research and genomics. It also distinguishes between primary and secondary uses of personal information. In a comparative and critical analysis of the normative landscapes of five countries, Québec (Canada), Germany, Australia, the United States and the United Kingdom, three barriers are identified: the impracticability of reconsent; the shortcomings of the review process (ethics and privacy) and certain multi-jurisdictional issues. Recommendations are proposed.

\section{Introduction}

From the late 1960 s to the early 1980 s, epidemiologists demonstrated the correlation between lung diseases and asbestos exposure. Their discoveries improved both the conditions of thousand of workers and construction practices. Such population-based projects $^{2}$ could not have been done in the current normative landscape. The main reasons are the obligations to seek specific individual consent and to obtain approval from review boards (privacy and ethics) in each institution where medical records are to be accessed.

Recently, certain authors ${ }^{3}$ have concluded that an adapted ethical framework was needed for population-based research, since the current framework is unable to address the questions of the "public good" associated with the goals and methods of longitudinal epidemiology. This paper, while not engaging in this debate, aims to provide some critical reflection. In an era where cohort and large-scale population studies are emerging alongside research infrastructures (databases and biobanks), it is necessary to re-examine applicable normative frameworks.

This text focuses on why population-based research is challenging current ethical and legal frameworks. In the first part, the similarities and differences between epidemiology, public health research and genomic research are highlighted. The second part begins with the distinction between primary and secondary access to personal data. A comparative and critical analysis of the multi-jurisdiction normative landscapes in Canada, Germany, Australia, the United States and the United Kingdom follows, focusing on common difficulties and on the innovative solutions proposed for population research. Three major barriers are identified: 1) the multi-jurisdictional nature of a federated country; 2) the impracticability of re-consent; and 3) the 
shortcomings of review boards (ethics / privacy) in the evaluation of population-based research. In the third part, specific recommendations for future guidance in the evaluation of population research are proposed.

\section{PART I Population Research}

\section{i) Similarities and distinctions}

Population-based research (or population research) refers to research on human subjects where "the objectives aim to improve the health of populations and discover interventions that raise the baseline health status of entire communities. This term is used in contrast to "disease-based research", whose goal is to ameliorate or cure a particular disease, regardless of its membership in a particular community." A key feature of population research is the identification of risk factors. Population research is based on observational studies and comparisons of disease rates. It includes socioeconomic and environmental data, as health determinants, to characterize the population under study. The parameters may be a disease rate, the prevalence of an exposure, or some measure of association between exposure and disease. The sample is generally large (enough to be statistically representative of the target population) and the data often collected by a multitude of researchers, in many institutions and countries (to compare populations). Box 1 proposes a comparison of population research and disease-oriented research.

\section{Box 1: Distinctive characteristics of population-based research and disease-based research}

\begin{tabular}{|c|c|c|}
\hline & Population-based Research & Disease-based Research \\
\hline Objectives & $\begin{array}{l}\text { Improve health of population } \\
\text { Discover interventions to raise health } \\
\text { status }\end{array}$ & $\begin{array}{l}\text { Treat or cure specific disease with } \\
\text { techniques or products }\end{array}$ \\
\hline Focus & $\begin{array}{l}\text { Oriented to groups, communities, } \\
\text { populations }\end{array}$ & $\begin{array}{l}\text { Oriented to individuals and families } \\
\text { regardless of where they live or under } \\
\text { what conditions }\end{array}$ \\
\hline Key feature & Identify risk factors & Characterize diseases \\
\hline Methods & $\begin{array}{l}\text { Observational studies, } \\
\text { Association studies, comparisons of } \\
\text { disease rates and exposures }\end{array}$ & $\begin{array}{l}\text { Case studies, clinical studies, } \\
\text { Descriptive research. }\end{array}$ \\
\hline $\begin{array}{l}\text { Socio- } \\
\text { environmental } \\
\text { factors }\end{array}$ & $\begin{array}{l}\text { Included as health determinants to } \\
\text { characterize the population at study }\end{array}$ & $\begin{array}{l}\text { Excluded; individuals are enrolled } \\
\text { regardless of where they live or under } \\
\text { what conditions }\end{array}$ \\
\hline Sample size & $\begin{array}{l}\text { Large enough to be representative of } \\
\text { the target population. }\end{array}$ & $\begin{array}{l}\text { Relatively small, variable according to the } \\
\text { parameters of the study }\end{array}$ \\
\hline Source of data & $\begin{array}{l}\text { Multiple in kind of data (socio-demo- } \\
\text { econo-environmental data) } \\
\text { Multiple in source (professionals, } \\
\text { institutions, regions, countries) }\end{array}$ & $\begin{array}{l}\text { Specific } \\
\text { Local, national, international }\end{array}$ \\
\hline Time scale & May be longitudinal & Generally limited in time \\
\hline
\end{tabular}

Population research is not a scientific discipline per se. Scientists who design population-research projects are mostly epidemiologists working in different fields of

Genomics, Society and Policy, Vol.5, No.1 (2009) ISSN: 1746-5354

(C) ESRC Genomics Network. 
medicine and biological sciences. In consequence, the methods and parameters of population research are largely those of epidemiology. ${ }^{5}$

An important aspect of epidemiology needs to be distinguished. The tasks of monitoring and surveillance for public health practice ${ }^{6}$ are part of epidemiology. These may employ research activities in their methods, but refer to different imperatives, such as emergency and targeted public health interventions, based on evidence of effectiveness.

Once population research is defined, further distinctions can be made regarding two of its fields: public health research and genomic research. Both are subject to ethical issues ${ }^{7}$. Public health research may be associated with a specific context, where intervention by public authorities (e.g. the government's department of health) is necessary. Its objectives are those generally attributed to public health - protection, disease prevention, health promotion, usually defined in legislation with specific and special powers of action. Research in public health is directed to problematic aspects of population health and consequently researchers will use health determinants derived from personal information to characterize a problem and to propose interventions. In contrast, genomic research aims to associate genetic determinants with specific conditions of health or diseases. It focuses on gene regulation, expression and interaction among genes and environmental factors. Its data are genetic and personal and come from multiple sources. Its tools are research infrastructures such as biobanks and databases. Box 2 summarizes the characteristics of these two types of population-based research.

Box 2 : Distinctive characteristics of two types of population-based research

\begin{tabular}{|c|c|c|}
\hline & Public Health Research & Genomic Research \\
\hline Objectives & $\begin{array}{l}\text { Protection, prevention, promotion } \\
\text { of population health }\end{array}$ & $\begin{array}{l}\text { Knowledge of gene-gene and gene- } \\
\text { environmental factors in the } \\
\text { population }\end{array}$ \\
\hline Results & $\begin{array}{l}\text { Targeted interventions based on } \\
\text { scientific evidence }\end{array}$ & $\begin{array}{l}\text { Discovery of targets, therapeutic } \\
\text { applications, lifestyle modifications }\end{array}$ \\
\hline Nature of data & Health determinants & Genetic and personal data \\
\hline Special tools & $\begin{array}{l}\text { Legislative powers, governmental } \\
\text { facilities }\end{array}$ & Biobanks and databases for research \\
\hline
\end{tabular}

Thus, population research has three specific features: the linkage of multiple types of data (clinical, socioeconomic, demographic, lifestyle, behavioral and environmental health determinants ${ }^{8}$ ) from multiple sources (registries, medical records, governmental databases, institutions, countries) and the procurement of a large number of samples (in databases and biobanks).

\section{PART II. Comparative Analysis}

The logic of the legal framework in Canada has its origins in the 1980 OECD Guidelines on the Protection of Privacy and Transborder Flows of Personal Data. ${ }^{9}$ In these fundamental guidelines, protection of personal data refers to a series of principles that govern all aspects of the "life cycle" of data, notably: collection, usage,

Genomics, Society and Policy, Vol.5, No.1 (2009) ISSN: 1746-5354

(C) ESRC Genomics Network. 
access and destruction. These principles are considered "as minimum standards which are capable of being supplemented by additional measures for the protection of privacy and individual liberties." 10 They have been integrated into the provincial and federal laws of both Canada and of the OECD member countries.

Two of the principles are particularly relevant to the secondary use of personal data in a research context:

\section{Para 9 Purpose Specification Principle \\ The purposes for which personal data are collected should be specified $\mathrm{n}$ ot la ter th an at the time of data collection and th $\mathrm{e}$ subsequent use lim ited to the f ulfilment of those purposes or such others as are not incompatible with those pu rposes and as are specified on each occasion of change of purpose.}

\section{Para $10 \quad$ Use Limitation Principle}

Personal data should not be disclo sed, made available or otherwise used for purposes oth er than thos e specified in acco rdance with Paragraph 9 except: $a$ ) with the consent of the data subject; or b) by the authority of law. ${ }^{12}$

Paragraph 9 indicates that the possible uses of personal data should be defined at the moment of the collection of data, and the subsequent use ("primary use") should be limited to these purposes. It also foresees potential "other" uses ("secondary uses"), which would not be incompatible with the specified primary use and which would be referred on each occasion of change to the relevant authority (e.g. privacy/ethics board) to evaluate their compatibility with the purposes initially specified. Paragraph 10 specifies that access or uses should logically be in accordance with the purposes previously defined, but allows two exceptions that could permit different uses of personal data: the consent of the data subject or an authorization by law.

In a number of countries, the multiplication of jurisdictions (e.g.provincial, federal) creates additional difficulties for multi-site projects. Population research can involve studies across multiple institutions, jurisdictions and countries. This affects the obligation of legislative compliance for researchers on different levels. In this second Part Québec, the normative frameworks of (Canada), Germany, Australia,

In summary:

$>$ Primary use is determined at the moment of collection

$>$ Secondary use must be in accordance with

1) the primary use agreed at the initial consent, or

2) a specific consent sought for the new purpose, or

3) authorized by law.

the UK and the USA will be described and critiqued, putting emphasis on the obstacles facing population research.

\section{ii) Québec - Canada}

The principles of the OECD are translated in the Acts regarding personal data in both the public and private sectors in Québec and in the applicable federal laws of Canada. Uses of personal information are restricted in all these laws. ${ }^{13}$ It is clearly specified that any further use, different from the initial purpose, must be in accordance with consent or by law. However, studies, research and statistics activities benefit from a

(C) ESRC Genomics Network. 
specific provision that stipulates that such uses of personal information are possible without consent. ${ }^{14}$ Research then is considered as a "compatible secondary use" of personal information. ${ }^{15}$ Access must be authorized by a privacy board (e.g. Access Commission in Québec) ${ }^{16}$ and requests will be evaluated according to two criteria: the necessity of nominative personal information for the activity and the confidentiality measures to protect the information. ${ }^{17}$ Authorization is granted for a limited period and information must be destroyed at the end of the project.

Interestingly, the Canadian federal legislation for the private sector introduced a third criterion: the "impracticability to obtain consent". There is no such mention in the federal Privacy Act for public bodies, nor in the Québec legislation. The Canadian Institutes of Health Research refined this criterion in their Best Practices for Protecting Privacy in Health Research: "Seeking consent from individuals for the use of their personal data may be considered impracticable when there are difficulties in contacting or notifying individuals for reasons such as: the size of the population being researched; the proportion of prospective participants likely to have relocated or died since the time the personal information was originally collected; or the lack of an existing or continuing relationship between prospective participants and the data holder who would need to contact them (e.g. a patient database that does not have a regular follow-up program to maintain a complete and accurate record of changes in registrants' contact information over time); such that: there is a risk of introducing bias into the research because of the loss of data from segments of the population that cannot be contacted to seek their consent, thereby affecting the validity of results and/or defeating the purpose of the study; or the additional financial, material, human, organizational and other resources needed to obtain consent could impose a hardship or burden on the researchers or organization so burdensome that the research could not be done". ${ }^{18}$

As concerns medical records in health establishments in Québec, the same logic of restricted use and specific consent applies under statute. ${ }^{19}$ But, the director of professional services may waive the obligation of consent and approve access requests for study, teaching or research purposes, if the criteria of the Access Commission are met (necessity and confidentiality) and if the project is in accordance with "accepted standards of ethics or scientific integrity". ${ }^{20}$ A specific approval of an ethics committee $^{21}$ is therefore necessary. These standards consist of a plethora of norms, the most important in Canada being the Tri-Council Policy Statement: Ethical Conduct for Research Involving Humans. ${ }^{22}$ According to the Statement, "Secondary use of data refers to the use in research of data contained in records collected for a purpose other than the research itself. Common examples are patient or school records or biological specimens, originally produced for therapeutic or educational purposes, but now proposed for use in research. This issue becomes of concern only when data can be linked to individuals, and becomes critical when the possibility exists that individuals can be identified in the published reports." 23 The Statement offers no guidance for longitudinal, epidemiological or biobanking endeavours. ${ }^{24}$ Currently under revision, the new draft Statement proposes that ethics approval "does not apply to secondary use of information that is anonymous, anonymized or deidentified/coded and where the research team has no access to the code. For example, this article [ethics approval for secondary use] does not apply to a researcher who

Genomics, Society and Policy, Vol.5, No.1 (2009) ISSN: 1746-5354

(C) ESRC Genomics Network. 
receives a de-identified dataset from an organization, but who does not have access to a code that permits re-identification of individuals". ${ }^{25}$

In the provinces of Ontario and Alberta, ethics committees studying requests for secondary uses have an additional criterion: balancing the public interest. In the case of Ontario, the public interest is associated with the necessity criterion or the anticipated public or scientific benefit of the research. ${ }^{26}$ In Alberta, ethics review boards have to balance the necessity (access to health information for research) with confidentiality (protection of privacy) in order to determine if the first "outweighs to a substantial degree $" 27$ the second. Alberta legislation provides further helpful criteria: the research ethics board must consider the degree to which the proposed research may contribute to (a) identification, prevention or treatment of illness or disease, (b) scientific understanding relating to health, (c) promotion and protection of the health of individuals and communities, (d) improved delivery of health services, or (e) improvements in health system management. ${ }^{28}$

As mentioned by the Québec Advisory Group on Governance of Databanks and Biobanks used for Health Research, the normative framework is not well adapted to the reality of research with databases where multiple projects may be carried out over an undetermined period of time. ${ }^{29}$ Therefore, a strict interpretation of the requirements for secondary uses would stop research projects in epidemiology, in both public health and genomics. For these reasons, the Québec Advisory Group has recommended the modification of relevant legislation. ${ }^{30}$ In addition, the variability of understanding among and interpretation by ethics review boards imposes enormous burdens for multi-site research projects, to say nothing of international collaborative projects.

\section{ii) Germany}

In Germany, freedom of research is guaranteed, among other basic human rights, by constitutional law ${ }^{31}$ but, as in other countries, it must conform to different privacy and confidentiality rules. The most important pieces of legislation are the Federal Data Protection Act 2001 (FDPA) and the Data Protection Acts (DPA) of the 16 German states.

The FDPA stipulates that personal data obtained for scientific purposes have to be rendered anonymous as soon as possible. ${ }^{32}$ Any processing of personal data is possible if the following cumulative conditions are met: the processing has to be necessary for the conduct of scientific research; the interest in the research has to outweigh significantly the interests of the data subject with regard to the change of the purpose; and the purpose of research could not be achieved by other means without unreasonable expenditure or indeed at all. ${ }^{33}$ By creating these conditions the legislators emphasized the importance of the principle of proportionality with regard to the change of purpose. ${ }^{34}$

For its part, the German National Ethics Council suggested a declaration of consent containing options so as to respect the autonomy of people participating in research more directly. ${ }^{35}$ It also attenuated some limitations on consent ${ }^{36}$ by proposing options as to duration (e.g. five or 10 years) and the nature of research (e.g. only for this project; all research on cancer; all health research), allowing broad consent as an option. It is also interesting to note that the German Council has stated that "It is in

(C) ESRC Genomics Network. 
the public interest for biobanks to be available for medical research. They should therefore be at the disposal of as large a group of interested researchers as possible. "37

Recognizing that research rarely benefits an individual per se, but only as a member of a specific group or as a carrier of particular characteristics, but taking for granted that researchers often need individual data (microdata) to start with, the Berlin Data Protection Commissioner proposed a way to mitigate the accumulation of conditions on privacy and confidentiality. ${ }^{38}$ He proposed to introduce a legally protected "research secret" analagous to medical secrecy in the German Criminal Code. ${ }^{39} \mathrm{He}$ argued that combined with "pseudonymisation" of data (i.e. coding), such a research secret could be an appropriate measure to protect personal information. This has also been proposed in the Telematic Platform for Medical Research Networks report. ${ }^{40}$

\section{iii) Australia}

In Australia, similar to other federations, the process of compliance with legislation and guidelines on data protection is complex. The National Health and Medical Research Council (NHMRC) expressed the view that:
"The curren t state of privacy reg ulation in Australia is entire ly unsatisfactory. Its complexity is impacting on the proper provision of health care and the conduct of important health and $\mathrm{m}$ edical research, in addition to creating significant unnecessary compliance costs."

The Commonwealth Privacy Act ${ }^{42}$ (Privacy Act), enacted in 1988, provides the regulatory framework for the protection of personal information in all national States. Its application was extended to the private sector in 2000, and in particular to the collection, use and disclosure of health information. It thus applies to many fields, including health and human research. Most Australian States have enacted legislation on privacy ${ }^{43}$ or health information protection. ${ }^{44}$

The Privacy Act proposes a "public interest test" with criteria that a Human Research Ethics Committee (HREC) must apply to health research:

the value and public importance of the research;

the likely benefits of the participation;

whether the research design can be modified;

the financial costs of not proceeding with the research;

the type of personal information being sought;

the risk of harm to individuals, and

the extent of a possible breach of privacy. ${ }^{45}$

It is important to note that the current definition accompanying the above test states that the public interest of research must "substantially outweigh" in the protection of privacy. This has led to HRECs taking a conservative approach in their reviews of research projects. ${ }^{47}$ Some authors consider that the trade-off between public good and privacy is doing more harm than good. ${ }^{48}$ Another, with irony, asked whether "the time has come for Australia to have public interest commissioners who can powerfully advocate for the public interest in high-quality health research" ${ }^{49}$

With this perspective in mind, the NHMRC recently adopted new guidelines. ${ }^{50}$ The most interesting principle of these is the provision on "future use of data and tissue in

Genomics, Society and Policy, Vol.5, No.1 (2009) ISSN: 1746-5354

(C) ESRC Genomics Network. 
research" which may be specific, extended (closely related or in the area of the original project) or unspecified (any future research). ${ }^{51}$ Provision 2.2.18 stipulates that access is conditional on consent, but consent can be waived by the ethics committee.

The Australian Law Reform Commission (ALRC) is currently reviewing the Australian privacy laws so as to make recommendations. ${ }^{52}$ Protection of health information and research with personal information are an important part of the consultation. The proposed "research exception" to the use and disclosure of personal information ${ }^{53}$ includes considering: a) the "necessity for research", which includes activity preliminary to research such as the creation of databases $;{ }^{54} b$ ) the "impracticability of seeking individual consent", which means more than incurring some expense or effort. The obstacles must be real and they must be significant; ${ }^{55}$

c) the "HREC's review and its satisfaction that the public interest outweighs the public interest in maintaining the privacy protection": the ALRC has attenuated the public interest balance by deleting the word "substantially"; d) the "conformity with the rules issued by the Privacy Commissioner", which has been asked, among others, to provide guidance on "not reasonably identifiable" criteria related to personal information; ${ }^{56}$ and e) "a reasonable belief that the recipient of the information will not disclose the personal information in a form that would identify the individual or from which the individual would be reasonably identifiable".

One of the main goals of this initiative is to harmonize State and Federal law, in both the private and public sectors, in order to achieve national consistency. The final report and recommendations were delivered to the Attorney-General in May 2008. ${ }^{57}$

\section{iv) United States ${ }^{58}$}

In the US, the Privacy Rule ${ }^{59}$, a Federal regulation under the Health Insurance Portability and Accountability Act (HIPAA) of 1996, protects certain health information in entities covered by the Rule. ${ }^{60}$ Also known as the Standards for Privacy of Individually Identifiable Health Information, the Privacy Rule was adopted to protect the privacy of health information that identifies individuals, whether living or deceased (called Protected Health Information - PHI). In general, the Privacy Rule overrides State laws regulating the privacy of health information but if they are not contrary to a provision of the Privacy Rule, both remain in full force and effect, so that covered entities will have to follow State laws in addition to the Privacy Rule.

It is important to emphasize that the Privacy Rule does not apply to research per se; it applies to covered entities (e.g. health care providers or clearinghouse), which may or may not include researchers. The Rule may affect researcher access to information, but it does not regulate the research directly. The decision whether an individual researcher must comply with the Privacy Rule is a fact-sensitive decision determined on a case by case basis.

Within the frame of the Privacy Rule, either individual research subjects give their consent to the use of personal data, or the REB or the Privacy Board ${ }^{61}$ waives the requirement of consent and gives an authorization to access the data without it. When an authorization is obtained for research purposes, the Privacy Rule requires that it be used only for that specific research study, and not for nonspecific research or for future and unspecified projects. It is also possible to have access to a limited data set

Genomics, Society and Policy, Vol.5, No.1 (2009) ISSN: 1746-5354

(C) ESRC Genomics Network. 
without obtaining an authorization, by signing a data use agreement with the entities concerned, which establishes conditions on which researchers can use the data.

It is interesting to underline that de-identified health information is exempt from the Privacy Rule. According to the Rule, to de-identify health information, 18 data elements including ZIP codes, ages and dates, must be removed. Designed to encourage researchers to use de-identified information, the standard appears unsuitable for much epidemiological, health services and other population-based research. ${ }^{62}$ A Data Use Agreement for accessing a limited data set is the way to solve this difficulty; but since it deals with information deprived of identifiers, even if their number is minimal, it may not adequately suit the research purposes. Finally, to limit certain uses or disclosures of personal health information, including those for research purposes, to "the information reasonably necessary to accomplish the purpose", the Privacy Rule imposes a minimum necessary requirement on all permitted uses and disclosures of personal health information by a covered entity.

Most of the biomedical and behavioral research conducted in the United States is governed either by the Federal Policy for the Protection of Human Subjects (also known as the "Common Rule") ${ }^{63}$ and/or the Food and Drug Administration's (FDA) Protection of Human Subjects Regulations. ${ }^{64}$ Some authors have questioned the pertinence and the public gains of the Privacy Rule when research is already regulated by the federal Common Rule, ${ }^{65}$ which is designed to find a balance between legitimate concerns about privacy and the regulatory burdens on medical record research. ${ }^{66}$ Moreover, there is a major difference between the two rules: the "Common Rule addresses the overall welfare of interest of research subjects, whereas the HIPAA regulations pertain only to research subjects' privacy interests". ${ }^{67}$

A 'Certificate of Confidentiality' is another means to provide access and protect identifiable health information. They are granted by the National Institutes of Health $(\mathrm{NIH})$, the Centers for Disease Control and Prevention (CDC) and the FDA and other Federal agencies, for "studies that collect information which, if disclosed, could damage subjects' financial standing, employability, insurability, or reputation, or have other adverse consequences". Certificates of Confidentiality help to achieve research objectives and promote participation in research studies by protecting researchers and institutions from forced disclosure of such information.

This system in the USA has come under further criticism. In a survey of a large group of US epidemiologists regarding the influence of the HIPAA Privacy Rule on their research, two-thirds thought the rule had made research more difficult and a majority thought the rule had a negative effect on the protection of human subjects. ${ }^{68}$ Others have reported that the effect of the HIPAA is to discourage legitimate low-risk research, citing a $70 \%$ reduction in medical records research requiring ethics review in the first year of the HIPAA Rule. ${ }^{69}$ The Rule has also been criticized for creating bias, thereby undermining the validity of research results in patient registries. ${ }^{70}$ Finally, according to others, the major threat to the present system is the dysfunctional nature of ethics review. ${ }^{71}$ The American Medical Informatics Association has published a 'white paper' asking for a "national framework for secondary use of health data". ${ }^{72}$

(C) ESRC Genomics Network. 


\section{v) United Kingdom}

Research in the UK is guided by an array of intersecting limitations, each deriving its authority from different ethical, legal and policy sources. The resulting situation is "complicated". 73

The most important laws governing medical research using personal data are: the Data Protection Act 1998 (DPA), the common law on confidentiality, the Human Rights Act 1998 (HRA) ${ }^{74}$ and Section 60 of the Health and Social Care Act $2001 .^{75}$ In the late 1990's the confusion surrounding the DPA, HRA and common law of confidentiality forced research ethics committees and hospitals to adopt a conservative interpretation of the law; they were reluctant to support studies based on the use of identifiable personal data. ${ }^{76}$ Section 60 of the Health and Social Care Act 2001 was enacted in response to this situation, to allow organizations to obtain patients' identifiable information gathered for medical purposes in circumstances where it was impracticable to obtain informed consent from the patients concerned. ${ }^{77}$ This Act sets aside the common law duty of confidentiality for the use of medical records for specific purposes. Paragraphs 1 and 10 of Section 60 associate medical research with the public interest. ${ }^{78}$

For its part, Section 33 of the DPA provides a limited exemption for research and statistical purposes. The further processing of personal data for these purposes is not to be considered incompatible with the purposes for which the data were obtained, ${ }^{79}$ provided that it will not support measures or decisions with respect to particular individuals and the processing is not likely to cause substantial damage or distress to any data subjects. According to section 2 of the Act, which associates health information with sensitive data, the processing of this information for research purposes must respect the Statutory Instrument Order 2000, which enumerates circumstances in which sensitive personal data may be processed ${ }^{80}$ when it is in the substantial public interest or when it is necessary for research purposes. This has been interpreted to mean that: "Order 2000 specifies that the prohibition [of processing sensitive data] is removed where processing is necessary for research purposes that are in substantial public interest on condition that the relevant conditions of Section 33 of the UK Act are satisfied". ${ }^{81}$

Thus, there are three options for secondary use research in UK: i) use of personal data with consent or assent from the data subjects; ii) use of anonymised data; iii) use of personal data without explicit consent, under a public interest mandate.

Although the third option appears to be quite simple, it is a question of interpretation as to what constitutes "public interest", which has created some confusion. Some researchers have publicly denounced the criterion of an overriding public interest as "too ambiguous to be useful" and have urged authorities to specify under which circumstances access to personal records without consent should be allowed. ${ }^{82}$ In contrast, the Academy of Medical Science maintains that, should a narrow approach be adopted for the interpretation of public interest, it would seriously hamper medical research and undermine evidence-based medicine to the detriment of public health. ${ }^{83}$ The Wanless Report ${ }^{84}$ qualified the difficulty obtaining access to data as a "possible threat to public health research".

One report presented to the Ministry of Justice regarding the use and protection of personal information proposes to develop "safe havens" for population-based

Genomics, Society and Policy, Vol.5, No.1 (2009) ISSN: 1746-5354

(C) ESRC Genomics Network. 
research, in which the risk of identifying individuals would be minimized. ${ }^{85}$ To work within those environments, researchers should be accredited. The implementation of this recommendation will require new legislation.

In conclusion, ethics norms in all these countries are associated with "nominative information" or "identifiable personal data". By definition, any data still associated with anonymized or anonymous samples do not constitute personal information ${ }^{86}$ since they are irreversibly unlinked. In fact, anonymization means removing "the link between subjects' identifiers and the unique code" so that it is no longer possible "to trace the data and samples back to individual subjects". ${ }^{87}$ This measure is recommended in a number of international, ${ }^{88}$ regional $^{89}$ and national ${ }^{90}$ legal instruments.

However, "if data anonymization seems to be an interesting mechanism in terms of releasing the researcher from the responsibility which is imposed on anyone manipulating personal information, this mechanism has very little interest with regards to population research, especially if the researcher wants to maintain an "organic" link with the samples to be analysed." 91 There are many reasons why the identification of individuals may be needed: linkage within a database; linkage between databases; ensuring comparisons are meaningful; ensuring completeness of recruitment; investigation of social factors; analysis of trends over time; and assessing the applicability of primary research. ${ }^{92}$

To summarize, there are three major barriers in the actual legal frameworks we have examined on personal data protection that limit utilization of information for populational research: 1) the obligation to re-consent for secondary uses; 2) the evaluation by a committee for every change in the primary use including secondary uses; and 3) the variation among institutions in the interpretation of the two first elements. These barriers are largely attributable to the fact that "there is no population-based counterpart to the principle of autonomy and the practice of informed consent by individuals". 93

\section{PART III. Future Guidance}

Many similarities can be observed amongst the normative frameworks analyzed - all apply the OECD principles and most are under revision. In light of our comparative analysis, it becomes obvious that these principles have been interpreted restrictively by ethics and privacy review boards. The resulting effect is an overemphasis on individual consent and privacy. To attenuate the resulting burdens on populationbased research, four recommendations are proposed based on our comparative analysis. They could serve to guide both review boards in their evaluation and policy makers in their work in the future.

\section{i) Allow broad consent for research at the moment of collecting data}

As demonstrated, requiring an explicit consent is an issue in the secondary use of data for population research. Fortunately, there is an increasing tendency towards openness. ${ }^{94}$ Both in Germany and in the new Australian guidelines, a broad consent approach has been qualified as a "novel model"95 for access for research purposes. With a broad consent to the use of coded data, withdrawal is always possible. Obtained at the moment of collecting data, broad consent expands the future "primary

Genomics, Society and Policy, Vol.5, No.1 (2009) ISSN: 1746-5354

(C) ESRC Genomics Network. 
use" possibilities for population research and attenuates the problems of secondary uses for research.

\section{ii) Include the scientific necessity and the impracticability criteria}

Each country studied allows secondary uses of personal data based on the 'necessity' criterion. To date it has been interpreted restrictively, so only specific information is accessible and researchers have to request permission for every further use. The European Directive 95/46/EC accepted that scientific research is not an incompatible secondary use of personal health information. Thus, the obligation of consent can be waived if information is used for scientific purpose, and if "despite reasonable efforts, it would be impracticable to contact the data subject to seek his consent". ${ }^{96}$ Clearly, European regulatory authorities recognize the importance of scientific research and the context of limited resources in which it exists.

In Canada, only the federal legislation governing the private sector has recognized the criterion of the impracticability of obtaining individual consent. ${ }^{97}$ The criterion is further described in the research guidelines of the Canadian Institutes of Health Research, but there is no explicit reference to impracticability in the laws governing the public sector, where most of the personal information used for population research is stored. The impracticability criterion backed by the scientific compatibility of scientific research with primary purposes should underscore and justify an exemption from re-consent.

\section{iii) Apply proportionality of risks and reasonable identifiability evaluation}

The 'proportionality principle' serves to balance privacy rights and health research. It can take two forms: operating generally as a guide for ethics committee to evaluate research projects ${ }^{98}$ and specifically as concerns the identifiability of personal information. ${ }^{99}$ Indeed, a recent development in the USA demonstrated that new bioinformatic technologies may allow for identifiability even within large data sets. ${ }^{100}$ So, putting emphasis on anonymization and de-identification is prone to failure. It does not protect the subjects, is not compatible with research practice ${ }^{101}$ and puts enormous burdens on scientists and ethics committees to evaluate the risk of identifiability.

On the risk of identifiability, Working Group 29 on the 1995 European Directive proposed a "reasonable criteria", meaning that "a mere hypothetical possibility to single out the individual is not enough to consider the person as "identifiable". ${ }^{102}$ This is an interesting interpretation of the proportionality principle, as an appreciation of risk of identification. But since the evaluation of risks and of potential identifiability is subject to individual judgement and variation amongst evaluators, it is not clear how, in reality, it is going to be applied. Nevertheless, this pragmatic interpretation provides new possibilities regarding appreciation of the research protocol by ethics and privacy review committees.

\section{iv) Focus on agent not content: from privacy to confidentiality}

Many commentators on research ethics have criticized the privacy model of regulation. According to Manson and O'Neill, "All of these problems [identifiability, secondary uses] are consequences of trying to protect informational privacy by

Genomics, Society and Policy, Vol.5, No.1 (2009) ISSN: 1746-5354

(C) ESRC Genomics Network. 
regulating types of informational content, rather than types of action that use information." 103

The two OECD principles (purpose specificity and limited uses) are the origins of the normative framework. These principles determined the informational dimension ${ }^{104}$ of privacy rights. Privacy is known to have multiple components ${ }^{105}$ but two of them are particularly relevant to secondary uses of information: 1) control of information; and 2) secrecy and confidentiality. The first is about the control of the information by the research participant himself. From the professional point of view (i.e. the researchers), it is a matter of professional integrity to be faithful to the will of the person who gives the data and expects that the goals and uses agreed to will be respected. Fidelity is then associated with the collection of data or the primary use agreed at the moment of consent. Based on the ethical principles of self-determination and autonomy, it leads to the requirement of a specific individual consent (re-consent).

The second is related to the protection of the personal information in the context of a professional relationship. Confidentiality, via the professional secret and security measures, ${ }^{106}$ is the expression of that protection. The articulation of these principles is summarized in Figure 1. According to this schematization, it seems possible to respect both privacy and dignity rights by putting emphasis on confidentiality without the burdens associated with a specific control of information.

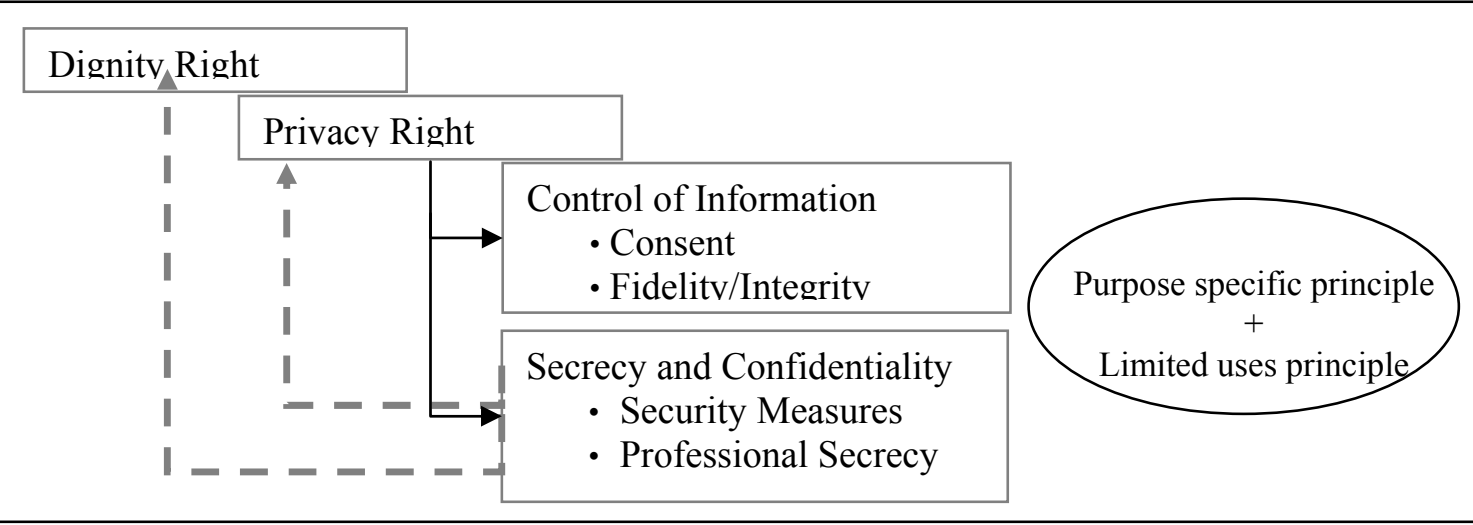

Figure 1: Scheme of secondary uses of personal data principles

We observed that a confidentiality model would be a more sustainable approach for population-based research. Focusing on 'agent not content ${ }^{107}$ in practical terms recognizes a professional duty of confidentiality for researchers, just as it exists for nurses, physicians and other professionals under the professional duty of medical confidentiality. Combined with security measures, a professional research secret could solve the current difficulties regarding population-based projects. As the Australian Law Reform Commission stated: "Duties of confidentiality recognise the dignity and autonomy of the individual, as well as the public interest in fostering a relationship of trust". 108

The obligation of confidentiality has the advantage of holding "between different types of agents, in many different social contexts". ${ }^{109}$ But this obligation needs to clearly define relationships among parties - the participants and the researchers. On the one hand, it is a privilege to access personal information and researchers have to treat data with respect. On the other hand, citizens must understand that their personal

Genomics, Society and Policy, Vol.5, No.1 (2009) ISSN: 1746-5354

(C) ESRC Genomics Network. 
information represents a valuable resource for scientists working to improve the quality of the diagnoses and treatments they receive.

\section{Conclusion: The complexity of ethical evaluation of the "public interest"}

The need to maintain trust in relation to the use of personal data in the research context has been the subject of much discussion. In the context of population research, where participants are not only individuals but also members of communities, populations and nations, important aspects of 'numbers' and 'representativeness' are intangible elements. They render the evaluation of population-based research by local ethics or privacy boards difficult. Scientists have criticized the public-interest notion as vague and ambiguous, but it is on precisely this voluntary, imprecise interface that the ethical evaluation of research resides. Neither ethics committees, which depend on research activity to exist, nor the researcher, that need the ethics imprimato to be publicly supported, have an interest in seeing one activity "substantially outweigh" the other: it is a question of public trust. Yet, both need to have better tools to enunciate the public interests in play. Perhaps these recommendations will help to redirect focus on essentials - agents - instead of concentrating excessively on consent. Population research is about the whole; we need to address the ethics in that context.

\footnotetext{
${ }^{1}$ Faculty of Law, University of Montreal. Correspondence to: knoppers@droit.umontreal.ca

${ }^{2}$ See for examples: J.C. McDonald et al. Dust exposure and mortality in chrysotile mining 1910-75. British Journal of Industrial Medicine 1980; 37: 11-24. R. Doll. Mortality from lung cancer in asbestos workers. British Journal of Industrial Medicine 1955; 12: 81. I.J. Selikoff, J. Churg, E.C. Hammond. Relation between exposure to asbestos and mesothelioma. New England Journal of Medicine 1965; 272: 560-5.

${ }^{3}$ A. Brand \& N. Probst-Hensch. Biobanking for epidemiological research and public health. Pathobiology 2007; 74: 227-238, at 230. G. Williams. Bioethics and large-Scale biobanking: Individualistic ethics and collective projects. Genomics, Society and Policy 2005; 1 (2): 50-66, at 55. B. M. Knoppers \& R. Chadwick. Human genetic research: Emerging trends in ethics. Nature Review Genetics 2005; 6: 75-79. N. Manson \& O. O’Neill. 2007. Rethinking Informed Consent in Bioethics. Cambridge University Press: 128-129.

${ }^{4}$ H.A. Taylor \& S. Johnson. Ethics of population-based research. The Journal of Law, Medicine \& Ethics 2007; 35 (2): 295-299.

${ }^{5}$ For a descriptive course on epidemiology, consult D. Goggon, G. Rose \& D.J.P. Barker. 1997. Epidemiology for the Unintiated. BMJ Publishing Group. http://www.bmj.com/epidem/epid.html

${ }^{6}$ For a distinction between public health research and public health practice, refer to: J.G. Hodge. An enhanced approach to distinguishing public health practice and human subjects research. The Journal of Law, Medicine \& Ethics 2005; Spring: 125-141. Centre for Disease Control and Prevention. Guidelines for Defining Public Health Research and Public Health Non-research. 1999. http://www.cdc.gov/od/science/regs/hrpp/researchDefinition.htm

${ }^{7}$ For public health see: N.E. KASS. Public health ethics: From foundations and frameworks to justice and global public health. Journal of Law, Medicine and Ethics 2004; 32: 232-242. For genomics see: T. Caulfield, et al. Research ethics recommendations for whole-genome research: Consensus statement, PLoS Biology 2008; 6 (3): e73.

${ }^{8}$ A. Brand \& N. Probst-Hensch, op.cit note 2.

${ }^{9}$ OECD, Guidelines on the Protection of Privacy and Transborder Flows of Personal Data, Paris, 23 septembre 1980. http://www.oecd.org/document/18/0,3343,en $2649 \quad 37441 \quad 1815186 \quad 1 \quad 1 \quad 1 \quad 37441,00 . h$ html.

${ }^{10}$ Ibid
${ }^{11}$ Ibid
${ }^{12}$ Ibid
}

(C) ESRC Genomics Network. 
${ }^{13}$ Act respecting Access to documents held by public bodies and the Protection of personal information, R.S.Q., c. A-2.1, s.65.1. Act respecting the Protection of personal information in the private sector, R.S.Q., c. P-39.1, s.13. Privacy Act, R.S.C. 1985, c. P-21, s.7; Personal Information Protection and Electronic Documents Act, SC 2000, c. 5., s.7

${ }^{14}$ Act respecting Access to documents held by public bodies and the Protection of personal information, R.S.Q., c. A-2.1, s.59 (5). Act respecting the Protection of personal information in the private sector, R.S.Q., c. P-39.1, s.18 (8). Privacy Act, R.S.C. 1985, c. P-21, s.8 (2)(j). Personal Information Protection and Electronic Documents Act, SC 2000, c. 5, s.7 (2) c.

${ }^{15}$ It is interesting to note that the "further processing of personal data for scientific purposes is not generally to be considered incompatible with the purposes for which the data have previously been collected" in Directive 95/46/EC of the European Parliament and of the Council of 24 october 1995 on the protection of individuals with regard to the processing of personal data on the free movement of such data. 1995. Official Journal of the European Union. 281. Preamble (29).

${ }^{16}$ Act respecting Access to documents held by public bodies and the Protection of personal information, R.S.Q., c. A-2.1, s.125. Act respecting the Protection of personal information in the private sector, R.S.Q., c. P-39.1, s.21; Privacy Act, R.S.C. 1985, c. P-21, s.7(2). Personal Information Protection and Electronic Documents Act, SC 2000, c. 5., s.7(2)c. There is no such obligation in the Privacy Act, the federal legislation for public bodies.

${ }^{17}$ Act respecting Access to documents held by public bodies and the Protection of personal information, R.S.Q., c. A-2.1, s.125 : "The Commission may, on a written request, grant a person or an agency the authorization to receive communication of personal information contained in a personal information file, for study, research or statistics purposes, without the consent of the persons concerned, if it is of the opinion: 1) that the intended use is not frivolous and the ends contemplated cannot be achieved unless the information is communicated in nominative form; 2) that the personal information will be used in a manner that will ensure its confidentiality. The authorization is granted for such period and on such conditions as may be fixed by the Commission. It may be revoked before the expiry of the period granted if the Commission has reason to believe that the authorized person or body does not respect the confidentiality of the information disclosed or the other conditions."

${ }^{18}$ Canadian Institute of Health Research. 2005. Best Practices for Protecting Privacy in Health Research. http://www.cihr-irsc.gc.ca/e/documents/et_pbp_nov05_sept2005_e.pdf

${ }^{19}$ An Act respecting Health and Social Services, R.S.Q. S-4.2, s.19.

${ }^{20}$ Ibid section 19.2

${ }^{21}$ Ibid section 19.1

${ }^{22}$ Canadian Institute of Health Research, Natural Sciences and Engineering Research Council of Canada, Social Sciences and Humanities Research Council of Canada, Tri-Council Policy Statement: Ethical Conduct for Research Involving Humans (1998 with 2000, 2002 and 2005 amendments).

Section 3. http://pre.ethics.gc.ca/english/policystatement/policystatement.cfm

${ }^{23}$ Ibid section 3.C.

${ }^{24}$ B.M. Knoppers. Ethics in health research evaluation, Health Law Review 2009; 17: $2 \& 3$.

${ }^{25}$ Interagency Advisory Panel on Research Ethics. Draft Second Edition of the Tri-Council Policy

Statement: Ethical Conduct for Research Conduct Involving Humans 2008; ch.5 at 49.

http://www.pre.ethics.gc.ca/eng/policy-politique/initiatives/draft-preliminaire/

${ }^{26}$ Personal Health Information Protection Act, S.O. 2004, c. 3 Schedule A, s. 44 (2): “A research plan must be in writing and must set out: (b) the nature and objectives of the research and the public or scientific benefit of the research that the researcher anticipates." From the ethics boards perspective: 44 (3)(c): "The public interest in conducting the research and the public interest in protecting the privacy of the individuals whose personal health information is being disclosed; and (d) whether obtaining the consent of the individuals whose personal health information is being disclosed would be impractical." ${ }^{27}$ Health Information Act, R.S.A. 2000, c. H-5, 50(1): "The research ethics board must (b) assess whether, in the opinion of the research ethics board, (i) the proposed research is of sufficient importance that the public interest in the proposed research outweighs to a substantial degree the public interest in protecting the privacy of the individuals who are the subjects of the health information to be used in the research."

${ }^{28}$ Ibid section $50(2)$ 
${ }^{29}$ FRSQ. 2006. Advisory Group on Governance Framework on Databanks and Biobanks used for Health Research.

At 58: "Authorization from the CAI or a director of professional services and consent by the user of health and social services fall within a legal framework designed for research in the context of a specific project taking place within a definite or definable period of time. This legal framework is ill suited to the reality and objective of data banks and biobanks, the use of which can be maximized if they are accessible for new research projects that could be carried out at a time unknown when the data and biological material were banked."

${ }^{30} \mathrm{Ibid}$

${ }^{31}$ Basic Law, BGBl. 1949, S. 1, §5.3.

${ }^{32}$ Federal Data Protection Act, BGB1.I 1990 S.2954, §40.2

${ }^{33}$ Ibid $\$ 14.2$ no. 9 and $\$ 28.3$ no. 4

${ }^{34}$ H.C. Künh. 2004. The implementation of the data protection directive 95/46/EC in Germany. In Implementation of the Data Protection Directive in Relation to Medical Research in Europe. D. Beveld et al, eds. Cornwall. Ashgate Publishing: 121.

${ }^{35}$ German National Ethics Council. 2004. Opinion on Biobanks. http://www.ethikrat.org/_english/publications/Opinion_Biobanks-for-research.pdf

${ }^{36}$ Ibid at 58 .

${ }^{37}$ Ibid at 75 .

${ }^{38}$ A. Dix, Berlin Commissioner On Data Protection And Freedom Of Information. 23-25 April 2006. Data Protection and Scientific Research. Spring Conference of European Data Protection Authorities.Budapest.

http://abiweb.obh.hu/dpc/springconference2006/confpapers/session4 alexander_dix.ppt

${ }^{39}$ Federal German Criminal Code, RGBl 1871, 127, §203. http://www.legislationline.org/upload/legislations/56/6f/b7295280cbb8cf24d08caa065790.pdf ${ }^{40} \mathrm{~J}$. Simon et al. A German experience. European Journal of Human Genetics 2007; 15: 528-532. "Regarding the endowment of biobanks with guaranteed research secrecy, the TMF report concluded that such a right would currently only apply to the doctor-patient relationships involved. For it to extend to entire biobanks, the corresponding legal regulations would have to be rephrased so as to include other medical and non-medical research personnel.":

${ }^{41}$ National Health and Medical Research Council. 15 January 2007. Submission PR 114.

${ }^{42}$ Privacy Act, 1988 No. 119. http://www.comlaw.gov.au/ComLaw/Legislation/ActCompilation1.nsf/framelodgmentattachme nts/409069FCABD20271CA25725C008385B5

${ }^{43}$ New South Wales, Privacy and Personal Information Protection Act (1998); Victoria, Information Privacy Act (2000); Northern Territory (2002)

${ }^{44}$ Australian Capital Territory, Health Records (Privacy and Access) Act (1997); New South Wales, Health Records and Information Privacy Act (2002); Victoria, Health Records Act (2001). For a quick overview and more information on applicable legislation in Australian States, consult Australian Law Reform Commission. 2007. Discussion Paper 72: Regulatory Framework for Health Information, table 56-1, at 1562, http://www.austlii.edu.au/au/other/alrc/publications/dp/72/73.pdf

${ }^{45}$ National Health and Medical Research Council. 2000. Guidelines under Section 95 of the Privacy Act 1988. s.3.2. http://www.nhmrc.gov.au/publications/synopses/ files/e26.pdf; National Health and Medical Research Council. 2001. Guidelines under Section 95A of the Privacy Act 1988, s.D4. http://www.nhmrc.gov.au/publications/synopses/_files/e43.pdf

${ }^{46}$ A similar approach is taken in the Alberta Health Information Act, op.cit note 37.

${ }^{47}$ See for example National Health and Medical Research Council. 15 January 2007. Submission PR 114. in Australian Law Reform Commission, op.cit. note 62, at 556.

${ }^{48}$ C.J. Thomson. Protecting health information privacy in research: How much law do Australians need? Medicine and the Law 2005; 183 (6): 315; K-A. O'Grady \& T. Nolan. Privacy: Bad for your health? The Medical Journal of Australia 2004; 180: 307.

${ }^{49}$ GR.B. Arnolda, Privacy : Bad for Your Health? Med J Aust.2004 181 (3): 174.

Genomics, Society and Policy, Vol.5, No.1 (2009) ISSN: 1746-5354

(C) ESRC Genomics Network. 
${ }^{50}$ National Health and Medical Research Council, Australian Research Council, Australian Vice-

Chancellor Committee. 2007. National Statement on Ethical Conduct in Human Research: 95.

http://www.nhmrc.gov.au/publications/synopses/e72syn.htm

${ }^{51}$ Ibid s.2.2.14

${ }^{52}$ For more information, look at Australian Law Reform Commission, op.cit.note 62.

${ }^{53}$ Australian Law Reform Commission, op.cit. note 62: table 56-1, at 1562, part H, Proposal 58-9, at 1691. http://www.austlii.edu.au/au/other/alrc/publications/dp/72/73.pdf

${ }^{54}$ Ibid at 1704

${ }^{55}$ Ibid at 1680 .

${ }^{56}$ Ibid at 1699 .

${ }^{57}$ The final report will be public only when tabled by Parliament. See Timetable of the Inquiry: $\mathrm{http}: / /$ www.alrc.gov.au/inquiries/current/privacy/timetable.htm

${ }^{58}$ The information for this section is based on HHS, NIH. 2003. Protecting Personal Health Information in Research: Understanding the HIPAA Privacy Rule. https://www.umkc.edu/research/protections/HIPAA/Documents/HIPAA_Booklet 4-14-2003.pdf ${ }_{59}$ Office for Civil Rights. 2002. Privacy Rule, 45 CFR $\S \S 160$ and 164. http://www.hhs.gov/ocr/privacy/index.html

${ }^{60}$ Genetic information is health information protected by the Privacy Rule. Like other health information, to be protected it must meet the definition of protected health information: it must be individually identifiable and maintained by a covered healthcare provider, health plan, or healthcare clearinghouse. See 45 C.F.R $\S \S 160.103$ and 164.501.

${ }^{61}$ Privacy Boards are new alternative review boards authorized by the Privacy Rule to review requests for alteration or waiver of a Research Authorization. If a covered entity is to use or disclose PHI on the basis of a waiver or an alteration of Authorization from a Privacy Board, the Board must be established in accordance with Section 164.512(i) of the Privacy Rule.

${ }^{62}$ J. Kulynych \& D. Korn. The Effect of the New Federal Medical-Privacy Rule on Research. New England Journal of Medicine 2002; 346 (3): 201; D.D. Wipke-Tevis \& M.A. Pickett. Impact of the Health Insurance Portability and Accountability Act on participant recruitment and retention. Western Journal of Nursing Research 2008; 30 (1): 39-53.

${ }_{63}^{63} 45$ CFR § 46. http://www.hhs.gov/ohrp/humansubjects/guidance/45cfr46.htm

${ }^{64} 21 \mathrm{CFR} \S 50$.

http://www.accessdata.fda.gov/scripts/cdrh/cfdocs/cfcfr/showCFR.cfm?CFRPart=50\&showFR=1; 21 CFR § 56.

http://www.accessdata.fda.gov/scripts/cdrh/cfdocs/cfcfr/showCFR.cfm?CFRPart=56\&showFR=1; see also 21 CFR § 312.

http://www.accessdata.fda.gov/scripts/cdrh/cfdocs/cfcfr/CFRSearch.cfm?CFRPart=312\&showFR=1; 21 CFR $\S 812$. http://www.accessdata.fda.gov/scripts/cdrh/cfdocs/cfcfr/CFRSearch.cfm?CFRPart=812\&showFR=1 ${ }_{65}$ J. Kulynych \& D. Korn. The New Federal Medical Privacy Rule. New England Journal of Medicine 2002; 347 (15): 1133; G.J. Annas. Medical privacy and medical research: Judging the new federal regulations. New England Journal of Medicine 2002; 346 (3): 216.

${ }^{66}$ R.J. Levine. Health research and the HIPAA Privacy Rule - Reply. Journal of the American Medical Association 2008; 299 (11): 1260.

${ }^{67}$ M. Barnes \& S. Krauss. The effect of HIPAA on human subjects research. BNA's Health Law Reporter 2001; 1026-41.

${ }^{68}$ R.B. Ness. Influence of the HIPAA Privacy Rule on health research. Journal of the American Medical Association 2007; 298 (18): 2164-2170.

${ }^{69}$ J.K. O'Herrin et al. HIPAA Regulations - Effect on medical record research. Annals of Surgery 2004; 239(6): 772-778.

${ }^{70}$ D. Armstrong et al. Potential impact of the HIPAA Privacy Rule on data collection in a registry of patients with acute coronary syndrome. Archives of Internal Medicine 2005;165: 1125-1129.

${ }^{71}$ N. Fost\& R.J. Levine. The dysregulation of human subjects research. Journal of the American Medical Association 2007; 298(18): 2196-2198.

${ }^{72} \mathrm{C}$. Safran et al. Toward a national framework for the secondary use of health data - an American Medical Informatics Association White Paper. Journal of the American Medical Informatics Association 2007; 14(1): 1-9.

Genomics, Society and Policy, Vol.5, No.1 (2009) ISSN: 1746-5354

(C) ESRC Genomics Network. 
73 "A research program must handle data in compliance with most of the following: the Declaration of Helsinki; the Data Protection Act; the Human Rights Act; confidentiality provisions of such statutes as the NHS Act, Public Health Act, Mental Health Act, Venereal Disease Act and Medicines Act; rulings on use of patient data made by the Secretary of State under the Health and Social Care Act; confidentiality standards of the General Medical Council; guidance from the Medical Research Council, the British Medical Association, and various medical Royal Colleges; security policies of the NHS Information Management and Technology Unit; data requirements of the NHS Information Standards Board; confidentiality and security advice of local NHS Caldicott Guardians; judgments of Research Ethics Committees; and common law." W.W. Lowrance. 2002. Learning from ExperiencePrivacy and the Secondary Use of Data in Health Research, London: Nuffield Trust: 13.

${ }^{74}$ It is interesting to note that the Human Rights Act introduced a privacy right in England and Wales. In the past, only common law confidentiality rules regulated the uses of personal information. See The Academy of Medical Science. 2006. Personal Data for Public Good: Using Health Information in Medical Research, at 28. http://www.acmedsci.ac.uk/index.php?pid=99\&puid=62

${ }^{75}$ These laws are in force in England and Wales, but not in Scotland and Northern Ireland, where health is a devolved matter and there are no formal legislative arrangements. A national Confidentiality and Security Advisory Group for Scotland, following a public consultation, proposed a set of minimum standards of good practice. According to the Academy of Medical Sciences "It is unlikely that the system could be successfully transposed to the larger research and health care setting in England and Wales." Ibid at 30.

${ }^{76}$ Ibid at 29.

${ }^{77}$ Department of Health. 2004. Section 60 of the Health and Social Care Act 2001: Consultation on Proposals to Revise Regulations. http://www.dh.gov.uk/en/Consultations/Closedconsultations/DH_4071402

${ }^{78}$ Health and Social Care Act 2001 (U.K.) 2001. c.15, s. 60, Par. 1: "The Secretary of State may by regulations make such provision for and in connection with requiring or regulating the processing of prescribed patient information for medical purposes as he considers necessary or expedient: (a) in the interests of improving patient care, or (b) in the public interest." Par. 10 : "Medical purposes means the purposes of any of the following: (a) preventative medicine, medical diagnosis, medical research, the provision of care and treatment and the management of health and social care services." http://www.opsi.gov.uk/acts/acts2001/20010015.htm

${ }^{79}$ Data Protection Act 1998 (U.K.) 1998. c.29, s.33 (2): "For the purposes of the second data protection principle, the further processing of personal data only for research purposes in compliance with the relevant conditions is not to be regarded as incompatible with the purposes for which they were obtained." http://www.opsi.gov.uk/acts/acts1998/19980029.htm

${ }^{80}$ The Data Protection (Processing of Sensitive Personal Data) Order 2000, S.I. 2000/417. http://www.opsi.gov.uk/si/si2000/20000417.htm

${ }^{81}$ D. Beyleveld et al. 2004. The UK's Implementation Directive 95/46/EC. In Implementation of the Data Protection Directive in Relation to Medical Research in Europe. D. Beyleveld et al (eds). Cornwall: Ashgate: 412.

${ }^{82}$ J. Peto, O. Fletcher \& C. Gilham. Data protection, informed consent and research. British Medical Journal 2004; 328:1029.

${ }^{83}$ The Academy of Medical Science, op.cit. note 92, at 41.

${ }^{84}$ D. Wanless. 2004. Securing Good Health for the Whole Population: Population Health Trends. Department of Health. http://www.hm-treasury.gov.uk/consultations and legislation/wanless/consult wanless03 index.cfm ${ }^{85}$ R. Thomas \& M.Walport. 2008. Data Sharing Review, Ministry of Justice: R.15. http://www.justice.gov.uk/docs/data-sharing-review-report.pdf

${ }^{86}$ M. Lacroix \& B.M. Knoppers. 2006. La Recherche en Génomique: de la Protection des Individus à l'Intérêt Commun. In Éthique de la Recherche et Santé Publique: où en est-on? C. Hervé et al (eds). Paris: Dalloz: 35-41.

${ }^{87}$ European Medicine Agencies. 2007. ICH Topic E15- Definitions for genetic biomarkers, pharmacogenomics, pharmacogenetics, genomic data and sample coding categories. http://www.emea.europa.eu/pdfs/human/ich/43798606en.pdf

${ }^{88}$ UNESCO. 2003. International Declaration on Human Genetic Data. 
http://portal.unesco.org/en/ev.php-

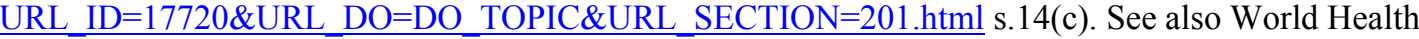

Organization. 2003. Genetic Databases. http://law.ed.ac.uk/ahrb/publications/online/whofinalreport.pdf

${ }^{89}$ Article 29 Data Protection Working Party. 2007. Opinion 4/2007 on the concept of personal data. s.6-7. http://ec.europa.eu/justice_home/fsj/privacy/docs/wpdocs/2007/wp136_en.pdf

${ }^{90}$ For Canada, consult: Canadian Institute of Health Research, Natural Sciences and Engineering Research Council of Canada, Social Sciences and Humanities Research Council of Canada, op.cit. note 20.

${ }^{91}$ M. Deschênes. 2007. Les Défis de la Recherche en Génétique dans l'Environnement Complexe de la Collaboration Internationale. In Système de Santé et Circulation de l'Information - Encadrement Éthique et Juridique. C. Hervé et al. Paris: Dalloz: 67 :75. [Author's translation] See also M. Lacroix \& B.M. Knoppers, op.cit. note 25 at 41.

${ }^{92}$ N. Black. Secondary use of personal data for health and health services research: why identifiable data are essential. Journal of Health Services Research and Policy 2003; 8: S:1:36-40.

${ }^{93}$ G.S. Omenn. Special challenges in applying genomics to population health. Journal of Biolaw and Business 2001; 4:4.

94 "[A] general movement in many countries seems to be towards informing the public/patients in general about a series of ways the data received from them may be used for a variety of common-good purposes, assuring them that safeguards and regulations are in place, then proceeding openly, being responsive to inquiries and so on. This would amount to a cultural change." in W.W. Lowrance, op.cit. note 91 , at 24 .

95 J.E. Lunshof et al. From genetic privacy to open consent. Nature Review Genetics 2008; 9: 406-411.

${ }^{96}$ Council of Europe, Committee of Ministers. 2006. Recommendation Rec(2006) 4 on Research on

Biological Material of Human Origin. s.22 ii)

https://wcd.coe.int/ViewDoc.jsp?id=977859\&BackColorInternet=9999CC\&BackColorIntranet=FFBB5

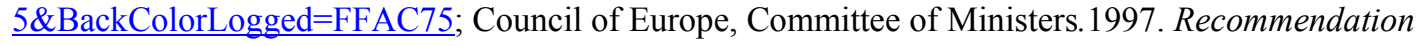
$R(97) 5$ on the Protection of Medical Data.

https://wcd.coe.int/ViewDoc.jsp?id=571075\&Site=CM\&BackColorInternet=9999CC\&BackColorIntra net=FFBB55\&BackColorLogged=FFAC75: s.12.2 ii)

${ }^{97}$ On impracticability, see D. Willison. Privacy and the secondary use of data for health research: experience in Canada and suggested directions forward. Journal of Health Services Research \& Policy 2003; 8:S:1:17-23; Canadian Institutes of Health Research. 2002. Secondary use of

personal information in health research: case studies. Ottawa: Public Works and Government Service Canada.

${ }^{98}$ See FRSQ, op.cit. note 47, at 38 .

${ }^{99}$ See Academy of Medical Sciences, op.cit. note 92. "Anonymization diminishes identifiability risk and it thus carries advantages for secondary users of data, if there is no need for longitudinal data, recontact or follow-up. As observed, "research on anonymised data is just research on cases, not persons". This is a crucial point for secondary research". W.W Lowrance, op.cit. note 91 at 27.

${ }^{100} \mathrm{~N}$. Homer et al. Resolving individuals contributing trace amounts of DNA to highly complex mixtures using high-density SNP genotyping microarrays. PLoS Genetics 2008; 4 (8) e1000167. doi:10.1371/journal.pgen.1000167

${ }^{101}$ See Black, op.cit. note 92.

102 "Recital 26 of the Directive pays particular attention to the term "identifiable" when it reads that "whereas to determine whether a person is identifiable, account should be taken of all the means likely reasonably to be used either by the controller or by any other person to identify the said person." This means that a mere hypothetical possibility to single out the individual is not enough to consider the person as "identifiable". If, taking into account "all the means likely reasonably to be used by the controller or any other person", that possibility does not exist or is negligible, the person should not be considered as "identifiable", and the information would not be considered as "personal data"." Opinion $4 / 2007$, op.cit note 28 , at 16

${ }^{103}$ N. Manson \& O. O'Neill, op.cit. note 2, at 119.

${ }^{104}$ As mentioned in R. v. Dyment: "privacy is composed of different dimensions: those involving territorial or spatial aspects, those related to the person and those that arise in the information context". We believe that it is the informational dimension of privacy that is in question within the context of population research. R. v. Dyment, [1988] 2 S.C.R. 417.

Genomics, Society and Policy, Vol.5, No.1 (2009) ISSN: 1746-5354

(C) ESRC Genomics Network. 
${ }^{105}$ See chapters on Solitude and Intimacy, Anonymity, Secrecy and Confidentiality, Control of Information, in E. Deleury \& D. Goubau. 1997. Le Droit des Personnes Physiques, 2e edition, Éditions Yvon Blais: 159-183.

106 “They may be 'physical, organizational and technological' and they must be set for the whole life cycle of the data, from their collection and uses to their destruction. These measures must be "reasonable given the sensitivity of the information, the purposes for which it is to be used, the quantity and distribution of the information and the medium on which it is stored" in An Act Respecting Access to Documents Held by Public Bodies and the Protection of Personal Information, op.cit. note 12,

s.63.1; An Act respecting the Protection of Personal Information in the Private Sector, op.cit note 12. s. 10. See also, Personal Information Protection and Electronic Document Act, op.cit note 12, Schedule 1, Principle 4.7.

${ }^{107}$ N. Manson \& O. O’Neill, op.cit. note 2, at 119.

${ }^{108}$ Australian Law Reform Commission, op.cit. note 62, Rec56.3, at 1560.

${ }^{109}$ N. Manson \& O. O’Neill, op.cit note 2, at 124. 